reminds us how often forecasts have been too pessimistic: Paul Ehrlich, doomwatcher and ecologist supreme, claimed in 1968 that in the 1970s "the world will undergo famineshundreds of millions of people are going to starve to death." Loraine himself takes a distributionist view: there would be plenty to eat for all if the world's resources were divided more equally. Doctors can play a part in urging a more rational food policy by reminding the public of the health benefits of diets in which much of the protein is obtained from cereals. Agricultural productivity could be increased enormously by capital investment-but that raises the spectre of the dependence of modern agricultural methods on fossil fuels. Long term, agriculture must surely be so organised and designed that it extracts most of its energy from the sun.

The sun-and the possibility of change in the earth's climate-is rarely included in any list of global concerns. Despite lucid exposition by popular writers such as Robert Ardrey ${ }^{3}$ the possibility that the earth may be engulfed by a new ice age is generally regarded as a science fiction fantasy. Is there any solid evidence to support this last doomwatcher's warning? John Gribben (of New Scientist) believes that there is, and he has recently collaborated with Douglas Orgill to write a fictional account ${ }^{1}$ of what might happen. The basis for their anxiety is that for most of the earth's recent history (the past two or three million years) much of its land surface has been permanently frozen. The "interglacial" period of warm climate we have experienced for the last 10000 years is one of the exceptions, not the normal state: and this interglacial has lasted longer than any of its predecessors. Where the experts disagree is on the speed with which the earth could descend into another ice age (with glacial ice one mile thick at the site of the city of Chicago). Some of the climatologists cited by Orgill and Gribben believe that six winters as severe as 1972, spaced fairly closely together, could return the northern hemisphere to the condition of 20000 years ago.

Most probably the doomwatchers will prove to be wrong most of the time-as Paul Ehrlich was shown to be. The disasters they predict are, however, so serious that governments and international agencies should take account of them. So far this seems to happen only when there is prolonged, noisy, public concern about an issue such as nuclear power. The countries of the world are now so interdependent that a better advance warning system is needed-as a matter of urgency.

${ }^{1}$ Hamilton A. Shutting the door on London's ever-rising tides. The Times 1979 Nov $26: 8$ (cols $1-3$ ).

2Loraine JA. Global signposts to the 21 st century. London: Peter Owens, 1979

${ }^{3}$ Ardrey R. The hunting hypothesis: a personal conclusion concerning the eqolutionary nature of man. New Jersey: Atheneum, 1976.

${ }^{4}$ Orgill D, Gribben J. The sixth winter. London: Bodley Head, 1979.

\section{Labile hypertension}

Patients whose arterial blood pressure is raised at some times and normal at others are said to have labile or borderline hypertension. Though no definition of "normal" blood pressure is really possible, in the WHO classification' (stage 1) labile hypertension is said to be present when the arterial blood pressure is sometimes above or sometimes below 14090 $\mathrm{mm} \mathrm{Hg}$. Most doctors are familiar with the patient whose initial high blood pressure falls to normal on subsequent visits: thus in a survey of 12371 people in Charlottesville, Virginia, labile hypertension was found in $11_{\%}^{\circ}$ of those tested. ${ }^{2}$ The high frequency of labile hypertension has been attributed $^{3}$ to a statistical phenomenon, regression towards the mean: the higher the arterial pressure is when first measured, the more likely it is to be lower on subsequent occasions. This dogma has, however, been disputed. ${ }^{4}$

The diagnosis of arterial hypertension is usually based on a single casual recording of the blood pressure, and most epidemiological data showing the risks of hypertension are also based on a single blood pressure reading. Since this first reading may be made under conditions of stress, perhaps not surprisingly subsequent readings are often lower. Which reading, however, is the important one, and which should we use for therapeutic decision making? In the past patients were often placed at rest in "near basal" conditions" for 20 to 30 minutes to see if the blood pressure would fall to normal. If it did so no treatment would be given. Further studies ${ }^{6}$ on such patients have shown that as many as $40^{\prime \prime}$ " may have raised levels of blood pressure under routine conditions of home life. Furthermore, Caldwell and his colleagues, in a long-term study of 471 patients, found that casual blood pressure readings were as accurate predictors of future cardiovascular risks as "near basal" recordings."

Arterial blood pressure varies considerably throughout the day. In normal people the average diurnal variation is $33 \mathrm{~mm}$ $\mathrm{Hg}$ systolic and $10 \mathrm{~mm} \mathrm{Hg}$ diastolic, though changes of even $100 \mathrm{~mm} \mathrm{Hg}$ systolic and $40 \mathrm{~mm} \mathrm{Hg}$ diastolic are not exceptional. " Larger total variations may be seen in persons who are hypertensive." Direct intravascular monitoring of the arterial blood pressure in ambulant patients has shown considerable variability in both systolic and diastolic blood pressures with a fall during sleep. ${ }^{10}$ In general, there is a good agreement between direct and indirect (cuff) readings of blood pressure, though in patients being treated for hypertension the indirect methods of blood pressure measurement tend to give pressure readings higher than those shown on direct recording. " Variation in blood pressure is therefore normal, and perhaps the existence of labile hypertension should not have been a surprise. Furthermore, while labile hypertension has been assumed inevitably to proceed to sustained hypertension, ${ }^{12}$ this hypothesis has never actually been tested. Kannel and his colleagues ${ }^{3}$ have even suggested recently that labile hypertension is a myth, using data from the Framingham study. They suggest that there is no difference in terms of the risk of stroke, heart disease, or heart failure between patients with labile hypertension and those with sustained hron rtension.

Perhaps the source of the controversy lies in the desire to attach diagnostic labels to patients. The level of arterial pressure represents a continuum, and the desire to attach a label to one subgroup (such as labile or prehypertension) may satisfy the physician's innate diagnostic need but it may not benefit the patient in the long run. ${ }^{13} \mathrm{~A}$ single blood pressure reading seems to be a reasonably good predictor of the risk of events to come: so possibly the higher the initial reading the more labile the pressure or the greater its diurnal swings. Labile hypertension may be a myth but only because it has been defined inaccurately. We need more information on its natural history.

\footnotetext{
Brod J, Hilleboe HE, Kimura N, et al. Arterial hypertension and ischaemic heart discase. $W H()$ Technical report series $1962 ; 231: 3-28$.

2 Carey RM, Reid RA, Ayers CR, Lynch SS, Mclain WL, Vaughan ED. The Charlottesville blood-pressure survey. Value of repeated bloodpressure measurements. FA.MA 1976;236:847-51.

Kolata GB. Is labile hypertension a myth ? Science 1979;204:489.
} 
' Carey RM, Ayers CR. Labile hypertension. Am f Med 1976;61:811-4.

"Alam GM, Smirk FH. Causal and basal blood pressures. 1. In British and Egyptian men. Br Heart $\mathcal{F} 1943 ; 5: 152-5$.

"Julius $\mathrm{S}$, Ellis $\mathrm{CN}$, Pascual AV, et al. Home blood pressure determination. Value in borderline ("labile") hypertension. FAMA 1974;229:663-6.

; Caldwell JR, Schork MA, Aiken RD. Is near basal blood pressure a more accurate predictor of cardiorenal manifestations of hypertension than causal blood pressure ? $\mathcal{F}$ Chronic Dis 1978;31:507-12.

* Gross M. Diurnal blood pressure variations in cerebrovascular disease. Ann Intern $M 1$ ed 1970;72:823-33.

" Richardson DW, Honour AJ, Fenton GW, Stott FH, Pickering GW. Variation in arterial pressure throughout the day and night. Clin Sci $1964 ; \mathbf{2 6}: 445-60$.

1" Littler WA, Honour AJ, Pugsley DJ, Sleight P. Circulation 1975;51: 1101-6.

"Littler W'A, Honour AJ, Pugsley DJ, Sleight P. The use of 24 hour blood pressure monitoring in the diagnosis and management of difficult hypertensive problems. Postgrad Med F 1976;52:(Suppl 7):119-22.

1: Eich RH, Peters RJ, Cuddy RP, Smulyan H, Iyons RH. The hemodynamics in labile hypertension. Am Heart f 1962;63:188-95.

1:3 Pickering GW. Normotension and hypertension: The mysterious viability of the false. $4 m \mathcal{F} M_{i} d 1978 ; 65: 561-3$.

\section{Cardiovascular mortality and altitude}

Studies of populations in the Andes suggest that both coronary artery disease and myocardial infarction are uncommon among residents at high altitude. Ramos et $a l^{1}$ found no case of myocardial infarction or of even moderate coronary artery disease in a consecutive series of 300 necropsies carried out at $14000 \mathrm{feet}$; and epidemiological studies ${ }^{2}$ in South America have shown that both angina of effort and electrocardiographic evidence of myocardial ischaemia are less common at such altitudes than at sea level. Similar findings have been reported in native residents of the Himalayas. ${ }^{3}$

Genetic differences and the absence or low frequency of known coronary risk factors among non-Western peoples affect the interpretation of comparisons between their mortality experience and that of whites; so the relation between cardiovascular mortality and residence at high and low altitudes needs to be examined in white populations as a separate study. Recent American research has yielded interesting results.

Mortimer et $a l^{1}$ looked at the variation in mortality from arteriosclerotic heart disease in whites in relation to altitude in the State of New Mexico. With increasing altitude they found a declining age-adjusted mortality from arteriosclerotic heart disease in men but not in women. They argued that the trend for men could not be explained by urban-rural differences, differences in cigarette smoking, racial mix (Spanish-Americans or other Americans), or by hardness of the water supplies, which in New Mexico is inversely related to altitude. Nevertheless, Buechley et al contended that the controls for racial differences had been inadequate, and that this factor rather than altitude accounted for the trend.

Most recently Voors and Johnson ${ }^{6}$ examined age-adjusted mortality from arteriosclerotic heart disease in whites by sex according to altitude in 99 of the 100 largest cities in the USA. The correlation between the two was modest and negative $(r-0.43)$, but was derived from extremely skewly distributed observations and is therefore open to challenge on statistical grounds. Similar doubts apply to the use of partial correlation techniques to show the absence of any relation between water hardness and arteriosclerotic heart disease mortality once altitude is accounted for. Nevertheless, none of the eight cities above 1300 feet $(400 \mathrm{~m})$ had an age-adjusted mortality for either sex as high as the median of the distribution for all 99 cities, and there was some evidence within water-hardness groups of declining mortality with increasing altitude.

The effects of selection for residence at altitude presumably have a larger part to play in New Mexico than across the major cities of the United States: in New Mexico the range of altitude and the maximum absolute elevation are both greater. These factors suggest that occupational selection in particular may help to explain the disparate findings for the sexes in New Mexico.

The implications of the American findings for residents of most European countries are less than clear. There are few major cities in Europe, east or west, above 2000 feet $(600 \mathrm{~m})$, and permanent residence virtually ceases at altitudes much below those of inhabited New Mexico. The scope even for observing an "altitude effect" in Europe is thus severely limited. Furthermore, any cross-European studies would be confounded by cultural and genetic differences. Despite this caution, some types of inquiry perhaps deserve attention. Within those countries with a moderate range of altitude it may be worth repeating the analysis of Voors and Johnson. ${ }^{6}$ Spain, France, and West Germany possibly have sufficiently homogeneous populations to enable this to be done. Next, information might be obtained from Caucasian populations living outside Europe at widely differing altitudes but in otherwise homogeneous conditions: thus East and South Africa may be natural laboratories. Finally, some Russian reports exist of investigations in the Caucasus and the Pamirs, where there is a moderate range of altitude of major residential centres, though less than in the United States. Much of this work is inaccessible to the average Western reader, but it may be worth exploring.

This is, however, a research topic of little practical importance to the British. None of our cities are as high even as 1000 feet $(300 \mathrm{~m})$ and the highest village in Britain is at less that 1500 feet $(450 \mathrm{~m})$. There is little prospect of reducing mortality from arteriosclerotic heart disease by relocating Milton Keynes, say, on the top of Dartmoor.

Ramos DA, Krüger H, Muro M, Arias-Stella J. Patologia del hombre nativo de las grandes alturas: investigacion de las causos de muerte en 300 autopsias, Bol Of Sanit Panam 1967;62:497-501.

2 Ruiz L, Figueroa M, Horna C, Peñaloza D. Prevalencia de la hipertension arterial y cardiopatia isquemica en las grandes alturas. Arch Inst Cardiol Mex 1969;39:474-89.

3 Singh I. WHO PAHO IBP me'ting of investigators on population biology at altitude, Washington DC, 1968.

- Mortimer EA, Monson RR, MacMahon B. Reduction in mortality from coronary heart disease in men residing at high altitude. $N$ Engl f Med 1977;296:581-5.

Buechley RW, Key CR, Morris DL, Morton WE, Morgan MV. Altitude and ischacmic heart disease in tricultural New Mexico. Am $\mathfrak{f}$ Epidemiol 1979;109:663-6.

${ }^{6}$ Voors AW, Johnson WD. Altitude and arteriosclerotic heart disease mortality in white residents of 99 of the 100 largest cities in the United States. F Chronic Dis 1979;32:157-62. 